\title{
Range shifts of Potentilla fruticosa on the Qinghai-Tibetan Plateau during glacial and interglacial periods revealed by chloroplast DNA sequence variation
}

\author{
A Shimono ${ }^{1}, \mathrm{~S} \mathrm{Ueno}^{2}, \mathrm{~S} \mathrm{Gu}{ }^{3}, \mathrm{X} \mathrm{Zhao}^{3}$, Y Tsumura ${ }^{2}$ and Y Tang ${ }^{1}$ \\ ${ }^{1}$ Environmental Biology Division, National Institute for Environmental Studies, Tsukuba, Ibaraki, Japan; ${ }^{2}$ Tree Genetics Laboratory, \\ Department of Forest Genetics, Forestry and Forest Products Research Institute, Tsukuba, Ibaraki, Japan and ${ }^{3}$ Northwest Plateau \\ Institute of Biology, Chinese Academy of Sciences, Xining, Qinghai, PR China
}

\begin{abstract}
The Qinghai-Tibetan Plateau is one of the most extensive habitats for alpine plants in the world. Therefore, the patterns of genetic variation in populations on the Plateau can reveal the detailed demographic history of alpine plants. We analysed the geographical structure of chloroplast matK sequence variation in Potentilla fruticosa L. (Rosaceae), a shrub currently found across the entire Plateau. We obtained sequence data from 508 individuals from 23 populations at sites ranging from the high-altitude interior to the relatively low-altitude northeastern Plateau. In the interior region, genetic diversity was high and included
\end{abstract}

ancestral haplotypes. In contrast, northeastern populations were characterized by relatively low genetic diversity and recently derived haplotypes. The estimated expansion time in the interior population was 17 times that in the northeastern population. These data suggest that $P$. fruticosa expanded its range on the Plateau during periods of climatic cooling and contracted to the interior region during warmer periods. Thus, the interior region acted as a refugium and greatly contributed to the diversification of $P$. fruticosa.

Heredity (2010) 104, 534-542; doi:10.1038/hdy.2009.158; published online 18 November 2009

Keywords: alpine plant; genetic diversity; landscape genetics; phylogeography; Pleistocene; refugia

\section{Introduction}

Global climate fluctuated greatly during the Pleistocene, causing the distributions of most species to change markedly, including range expansion and contraction and by founder events. Such range and demographic changes undoubtedly affect the geographical patterns of genetic variation within and among populations (Hewitt, 2004). Extensive molecular-based research has helped to identify areas where species survived and also to elucidate their subsequent spread, which resulted in their present-day distributions (Avise, 2000; Petit et al., 2003; Soltis et al., 2006).

Molecular studies have clearly shown, for example, the demographic histories of arctic and alpine plants in highlatitude regions (Hewitt, 2000; Abbott and Brochmann, 2003; Schonswetter et al., 2005). These plant species survived in unglaciated peripheral or nunatak refugia during glacial periods, when massive ice sheets covered these regions, and alpine species expanded from these glacial refugia after the last glacial period.

Contrasting demographic patterns to those in highlatitude regions have been suggested for alpine plants in

Correspondence: Dr A Shimono. Current address: Department of Ecology and Environmental Science, Umeå University, Umeå 901-87, Sweden. E-mail: ayako@tibetplant.com.

Received 24 December 2008; revised 22 October 2009; accepted 22 October 2009; published online 18 November 2009 both temperate and tropical regions, where the cooler periods of the Pleistocene had a crucial role in their expansion (Ikeda et al., 2006; Assefa et al., 2007). During warm periods, alpine species probably retreated to a number of refugia, and they probably experienced several cycles of range contraction and expansion in response to the climatic fluctuations of the Pleistocene (Koch et al., 2006). However, genetic patterns of alpine plants in temperate and tropical regions are complex, and it is difficult to detect clear range shifts because alpine habitats are highly fragmented, having never been connected during glacial or interglacial periods. High-elevation populations may have mainly migrated upslope and downslope, thus remaining isolated throughout the palaeoclimatic cycles, with the result that there was little opportunity for inter-population gene flow (DeChaine and Martin, 2005). Moreover, stochastic demographic events, including extinction, population isolation and long-distance dispersal, can have more noticeable effects in fragmented habitats than in connected habitats, further obscuring geographic genetic patterns.

The Qinghai-Tibetan Plateau occupies an area of 2.5 million $\mathrm{km}^{2}$, with an average altitude of $4500 \mathrm{~m}$. Although it is the plateau with highest altitude in the world, it was not covered by massive ice sheets during the last glacial period (Shi, 2002). Limited ice coverage during glaciations resulted in less habitat fragmentation, enabling the Plateau to serve as a refuge for many alpine 
plants. More than 12000 species of plants grow on the Plateau, and it is especially rich in endemic species and genera (Lopez-Pujol et al., 2006). Therefore, it is one of the most biologically important and outstanding examples of alpine habitat. The patterns of genetic variation in present-day plant populations on the Plateau are expected to exhibit deep divergence and outstanding diversification, which should allow us to reconstruct their demographic history in more detail.

A rough demographic history of alpine plants can be deduced from palaeoenvironmental changes. Fossil pollen records suggest that the typical vegetation of the Plateau during the last glacial period was adapted to permafrost-steppe, tundra or desert habitats (Yu et al., 2000), although the temperature was $6-9{ }^{\circ} \mathrm{C}$ lower than at present (Shi, 2002). These plant communities also developed in the interior of the Plateau during the postglacial period, when forests became widespread on the eastern Plateau (Herzschuh et al., 2006). After the forest retreat, populations may have then expanded from the interior of the Plateau towards its eastern margin. Therefore, results of palaeovegetation studies indicate that the interior Plateau, with its relatively high altitudes, may have provided habitats for alpine plants throughout the glacial and interglacial periods. However, fossil pollen data from the Plateau before the last glacial period are extremely rare and insufficient for the construction of palaeovegetation maps covering the entire region, and the extent of the glacial advance on the Plateau is still under debate (Zheng et al., 2002; Lehmkuhl and Owen, 2005).

The geographical pattern of genetic variation within species of the Qinghai-Tibetan Plateau should provide insight into the above-mentioned glacial and interglacial demographic changes. Recent phylogeographic studies have examined the demographic history of alpine plants across the Plateau (Chen et al., 2008; Yang et al., 2008; Wang et al., 2009). Wang et al. (2009) suggested that Aconitum gymnandrum has survived on high-altitude parts of the central Plateau throughout the Quaternary. In contrast, Metagentiana striata and Pedicularis longiflora probably expanded from refugia on the eastern edge to the central Plateau during the interglacial and postglacial periods (Chen et al., 2008; Yang et al., 2008). Therefore, these three investigated alpine species do not share a common phylogeographical history. To understand climatic changes and past distributions of alpine plant species on the vast Plateau, further study of the extensive high-elevation area is required, for which sampling is difficult even today.

For phylogeographic study, we selected the alpine shrub Potentilla fruticosa L. (Rosaceae) as a representative of the alpine plants that currently grow throughout the Qinghai-Tibetan Plateau. P. fruticosa is a small, longlived, deciduous shrub species that is widely distributed in alpine meadows, grasslands and forest margins. Its altitude ranges from 400 to $5000 \mathrm{~m}$, according to specimen records in China (Li et al., 2003). Its flowers are selfincompatible and are pollinated not only by Hymenoptera, mainly wild bees, but also by Diptera, Lepidoptera and occasionally by Hemiptera (Guillen et al., 1995). The mature achenes are covered with long hairs, which presumably aid in their dispersal by wind (Elkington and Woodell, 1963). We examined the spatial pattern of chloroplast DNA variation in $P$. fruticosa populations in habitats across the northeastern and interior Plateau. Our objective was to test the following two hypotheses: (1) that the interior of the Plateau served as a refugium for $P$. fruticosa during interglacial periods and (2) that the range of this species expanded eastwards from the interior of the Plateau.

\section{Materials and methods}

\section{Plant material and study sites}

Leaves from P. fruticosa were collected in 2006 and 2007 from 23 sites distributed across the Qinghai-Tibetan Plateau, from the interior to the northeastern region (Figure 1). At each site, leaves were collected from spatially separated individuals; 508 samples were collected in total (Table 1). The leaf material was dried in silica gel and stored at room temperature.

\section{DNA extraction and sequencing}

Total DNA was extracted from dried leaf material using a modified version of the hexadecyltrimethyl ammonium bromide (CTAB) method (Murray and Thompson, 1980).

Part of the matK gene of the chloroplast DNA was amplified by PCR using the AF and $8 \mathrm{R}$ primers (Ooi et al., 1995). PCR was performed in a total volume of $15 \mu \mathrm{l}$, containing $1 \times$ PCR buffer, $2.5 \mathrm{mM} \mathrm{MgCl}_{2}, 0.2 \mu \mathrm{M}$ of each primer, $0.2 \mathrm{mM}$ of each dNTP, $0.25 \mathrm{U}$ Ampli Taq Gold (Applied Biosystems, Foster City, CA, USA) and $20 \mathrm{ng}$ of template DNA. PCR products were cleaned using the QIAquick PCR purification Kit (Qiagen, Tokyo, Japan).

Forward and reverse strands were cycle-sequenced with the same PCR primers, using a BigDye Terminator version 3.1 Cycle Sequencing Kit (Applied Biosystems). For the cycle-sequencing reaction, the thermal profile was 25 cycles at $96^{\circ} \mathrm{C}$ for $10 \mathrm{~s}, 50^{\circ} \mathrm{C}$ for $5 \mathrm{~s}$ and at $60^{\circ} \mathrm{C}$ for $4 \mathrm{~min}$. Products were analysed on an ABI 3730 automated sequencer (Applied Biosystems). Forward and reverse sequences were assembled using Vector NTI software (Invitrogen, Carlsbad, CA, USA). Sequences were compared visually with the original chromatograms to avoid reading errors. All sequences are accessible at GenBank (accession nos. AB458562-AB458594).

\section{Sequence analysis}

The DNA sequences were aligned using the CLUSTAL_X 1.81 software (Thompson et al., 1997) and refined manually. Indels were treated as a single character resulting from one mutation event.

Relationships among haplotypes were resolved by constructing a statistical parsimony network and a maximum parsimony tree. The statistical parsimony network was produced using the TCS version 1.13 software (Clement et al., 2000) with a 95\% statistical confidence limit, as outlined by Templeton et al. (1992). Maximum parsimony trees were constructed using the PAUP $4.0 \mathrm{~b} 10$ software (Swofford, 2003), applying a tree bisection and reconnection branchswapping algorithm. The consensus tree was estimated using a bootstrap approach with 1000 replicates. To determine the ancestral haplotype, Fragaria vesca was selected as an outgroup by referring to the phylogeny of the Rosaceae (Eriksson et al., 2003). Eriksson et al. (2003) reported that the clade including $P$. fruticosa comprises a number of Potentilla species along with several other 


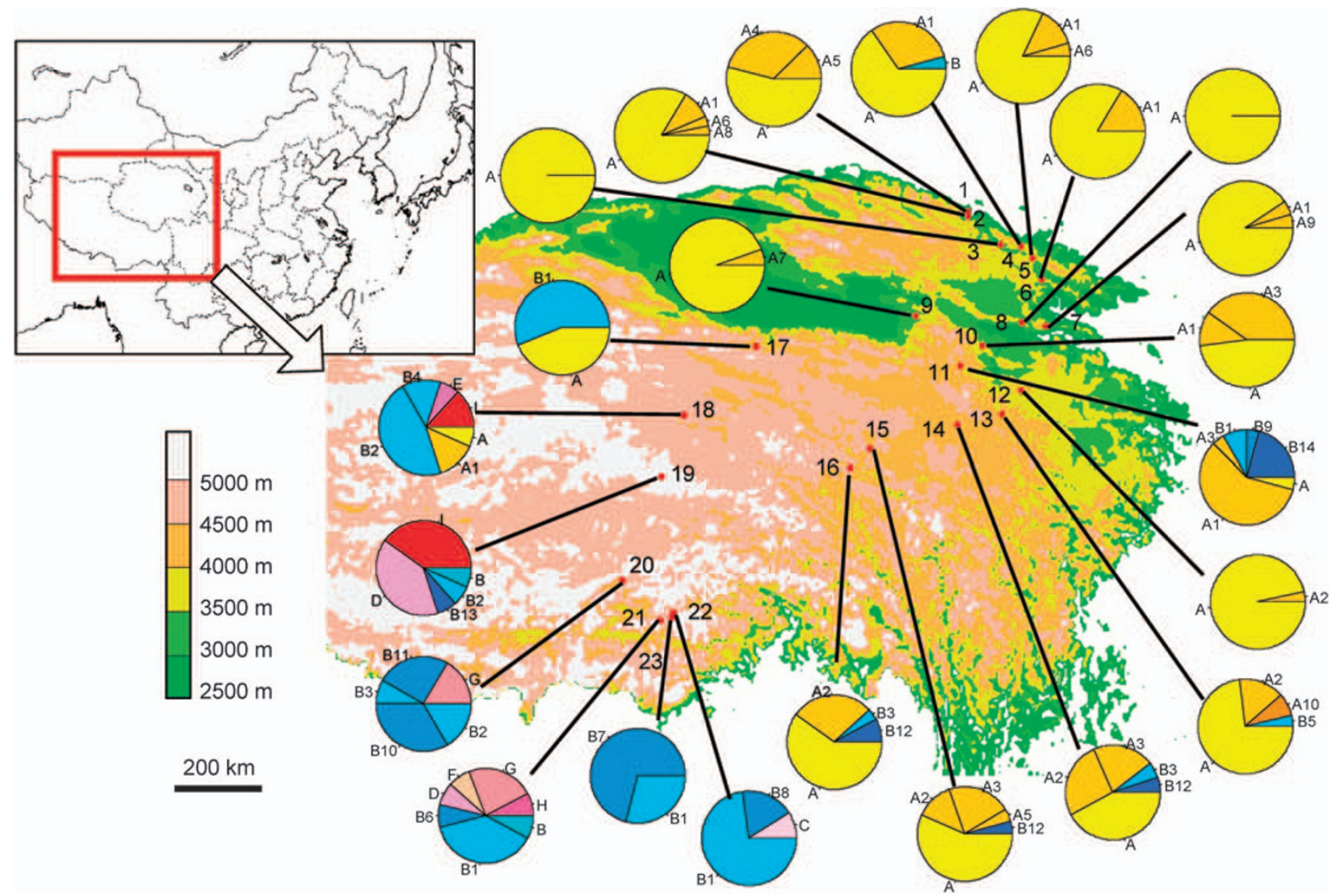

Figure 1 Map of the locations of the populations sampled in this study and the geographical distribution of cpDNA haplotypes detected in Potentilla fruticosa. cpDNA, chloroplast DNA.

Table 1 Population number, location, coordinates, altitude, number of samples $(N)$, number of haplotypes $(n h)$, nucleotide diversity $(\pi)$ and haplotype diversity $(h)$ with s.d. of the 23 populations of Potentilla fruticosa

\begin{tabular}{cccccccc}
\hline No. & Latitude & Longitude & $\begin{array}{c}\text { Alt. } \\
(m)\end{array}$ & $\mathrm{N}$ & $\mathrm{nh}$ & $\begin{array}{c}\pi(s . d .) \\
\left(\times 10^{-3}\right)\end{array}$ & $\mathrm{h}(\mathrm{s.d.})$ \\
\hline 1 & $38^{\circ} 47^{\prime}$ & $99^{\circ} 29^{\prime}$ & 2720 & 24 & 3 & $0.633(0.554)$ & $0.605(0.066)$ \\
2 & $38^{\circ} 40^{\prime}$ & $99^{\circ} 30^{\prime}$ & 3820 & 30 & 4 & $0.292(0.340)$ & $0.303(0.104)$ \\
3 & $38^{\circ} 05^{\prime}$ & $100^{\circ} 22^{\prime}$ & 2910 & 23 & 1 & 0 & 0 \\
4 & $38^{\circ} 03^{\prime}$ & $100^{\circ} 53^{\prime}$ & 3570 & 23 & 3 & $0.564(0.515)$ & $0.502(0.083)$ \\
5 & $37^{\circ} 47^{\prime}$ & $101^{\circ} 11^{\prime}$ & 3420 & 22 & 3 & $0.309(0.356)$ & $0.325(0.117)$ \\
6 & $37^{\circ} 20^{\prime}$ & $101^{\circ} 24^{\prime}$ & 3690 & 30 & 2 & $0.263(0.320)$ & $0.287(0.092)$ \\
7 & $36^{\circ} 19^{\prime}$ & $101^{\circ} 29^{\prime}$ & 3560 & 21 & 3 & $0.174(0.257)$ & $0.186(0.110)$ \\
8 & $36^{\circ} 22^{\prime}$ & $100^{\circ} 54^{\prime}$ & 3560 & 21 & 1 & 0 & 0 \\
9 & $36^{\circ} 28^{\prime}$ & $98^{\circ} 13^{\prime}$ & 3840 & 18 & 2 & $0.102(0.193)$ & $0.111(0.096)$ \\
10 & $35^{\circ} 51^{\prime}$ & $99^{\circ} 55^{\prime}$ & 3770 & 25 & 3 & $0.659(0.568)$ & $0.620(0.052)$ \\
11 & $35^{\circ} 25^{\prime}$ & $99^{\circ} 22^{\prime}$ & 4050 & 24 & 6 & $2.619(1.592)$ & $0.630(0.095)$ \\
12 & $34^{\circ} 54^{\prime}$ & $100^{\circ} 53^{\prime}$ & 3940 & 28 & 2 & $0.065(0.150)$ & $0.071(0.065)$ \\
13 & $34^{\circ} 24^{\prime}$ & $100^{\circ} 25^{\prime}$ & 3950 & 26 & 4 & $0.684(0.581)$ & $0.452(0.109)$ \\
14 & $34^{\circ} 08^{\prime}$ & $99^{\circ} 19^{\prime}$ & 4420 & 19 & 5 & $1.336(0.947)$ & $0.743(0.064)$ \\
15 & $33^{\circ} 33^{\prime}$ & $97^{\circ} 13^{\prime}$ & 4410 & 23 & 5 & $0.939(0.726)$ & $0.640(0.090)$ \\
16 & $33^{\circ} 06^{\prime}$ & $96^{\circ} 45^{\prime}$ & 4280 & 25 & 4 & $1.127(0.824)$ & $0.577(0.083)$ \\
17 & $34^{\circ} 12^{\prime}$ & $92^{\circ} 26^{\prime}$ & 4350 & 25 & 2 & $1.409(0.972)$ & $0.513(0.037)$ \\
18 & $29^{\circ} 54^{\prime}$ & $92^{\circ} 21^{\prime}$ & 4580 & 15 & 6 & $5.241(2.981)$ & $0.771(0.098)$ \\
19 & $32^{\circ} 50^{\prime}$ & $91^{\circ} 55^{\prime}$ & 5150 & 15 & 5 & $8.183(4.480)$ & $0.714(0.081)$ \\
20 & $30^{\circ} 32^{\prime}$ & $91^{\circ} 03^{\prime}$ & 4930 & 12 & 5 & $4.561(2.685)$ & $0.833(0.069)$ \\
21 & $29^{\circ} 43^{\prime}$ & $92^{\circ} 02^{\prime}$ & 4280 & 13 & 7 & $5.935(3.376)$ & $0.833(0.086)$ \\
22 & $29^{\circ} 54^{\prime}$ & $92^{\circ} 21^{\prime}$ & 4520 & 22 & 3 & $1.869(1.217)$ & $0.450(0.112)$ \\
23 & $29^{\circ} 48^{\prime}$ & $92^{\circ} 20^{\prime}$ & 4850 & 24 & 2 & $0.394(0.411)$ & $0.431(0.081)$ \\
\hline
\end{tabular}


using residuals from an isolation-by-distance regression across individuals, unusually high genetic distances between individuals within an area result in high elevations on the structural map. We selected a grid size of $50 \times 46$ to best represent the rectangular shape of the study area and a distance-weighting parameter of 1 . We also tested other grid sizes and a range of distanceweighting parameters (0.5-2) to confirm that qualitatively similar results would be obtained.

\section{Demographic analyses}

To test the hypothesis that the range of $P$. fruticosa expanded eastwards, we divided the populations into two regions, namely the northeast (sites 1-17) and the interior (sites 18-23), and analysed the demographic change according to a sudden expansion model by examining the mismatch distribution (the distribution of pairwise differences between haplotypes). This model assumes a sudden population growth from $N_{0}$ to $N_{1}$ that occurred $t$ generations ago, after which the population reaches demographic equilibrium (Rogers and Harpending, 1992). The mismatch distribution is usually multimodal in samples collected from populations at demographic equilibrium that have been of relatively stable size over time, but it is unimodal in populations that have experienced a recent demographic expansion (Rogers and Harpending, 1992). We used ARLEQUIN version 2.0 software for this implementation (Schneider et al., 2000). This software estimates three demographic parameters by a generalized nonlinear least-squares approach (Schneider and Excoffier, 1999), $\theta_{0}=2 u N_{0}$, $\theta_{1}=2 u N_{1}$ and $\tau=2 u t$, where $u$ is the mutation rate. The validity of this stepwise expansion model is tested by a parametric bootstrap approach simulating sum of squared deviations, which is also used to estimate confidence interval values of the estimated parameters.

\section{Results}

\section{Geographical distribution and phylogenetic analysis of haplotypes}

We analysed a total of 508 individuals from 23 populations of P. fruticosa on the Qinghai-Tibetan Plateau and detected 33 haplotypes by examining $\sim 1120 \mathrm{bp}$ of chloroplast DNA from the matK region. Variable sites among the 33 haplotypes were observed as 56 nucleotide substitutions and 2 indels, of which 18 were parsimony informative (Table 2). Haplotype A was dominant and widely distributed over the northeastern Plateau (Figure 1). Haplotypes A1 and B1 were also detected frequently in the northeastern and interior Plateau, respectively, whereas the other haplotypes tended to be restricted to local areas. Haplotype B especially occurred with low frequency in two disjunct areas, that is, in site 4 in the northeast and in sites 19 and 21 in the interior region.

Parsimony analysis produced 12 most-parsimonious trees, which required 80 steps (consistency index $=0.950$; retention index $=0.944$ ). The topology of the strict consensus tree of the 12 most-parsimonious trees is shown in Figure 2. The same topology was obtained using another outgroup, $P$. anserine. The haplotype network drawn by the statistical parsimony method also clearly supports this topology. Three haplogroups are apparent in both the parsimony tree and the haplotype network. The relationships among the haplotypes within each haplogroup are unresolved polytomies; that is, each haplotype network exhibits a star-shaped phylogeny. Geographically, the basal haplotype I and haplogroup 1, which consists of haplotypes $\mathrm{C}-\mathrm{H}$, were confined to the interior region (sites 18-22). Haplogroup 2, consisting of haplotype B and haplotypes derived from haplotype B, was widespread throughout the Plateau, but occurred with low frequency in the northeastern region. Haplogroup 3, consisting of haplotype $\mathrm{A}$ and the haplotypes derived from haplotype $\mathrm{A}$, was dominant and widely distributed over the northeastern region.

\section{Genetic diversity and spatial genetic structure}

Most interior populations (sites 18-23), which had widely divergent haplotypes (haplotypes C-I), exhibited high levels of nucleotide diversity (Table 1). In contrast, northeastern populations (sites 1-17) exhibited relatively low levels of nucleotide diversity, a tendency that was particularly noteworthy in populations occurring at altitudes below $4000 \mathrm{~m}$ (Table 1).

The AMOVA showed that $\sim 48.7 \%$ of the genetic variation occurred among populations, whereas $\sim 51.3 \%$ of the variation occurred within populations in the study area. The $\mathrm{F}_{\text {st }}$ value was $0.487(P<0.0001)$

Genetic landscape shape interpolation analysis produced a clear surface plot, showing that genetic distances increased towards the interior region (Figure 3a). Four high ridges were observed between site 19 and the adjacent sampling sites (Figure 3b).

\section{Demographic analyses}

The distribution of pairwise differences between plants from the northeastern populations (sites 1-17) was unimodal, indicating that the sudden expansion model is applicable (Figure 4a). The main expansion event was estimated to have occurred at $\tau=0.8$ (95\% confidence interval, 0-2.1). The newly derived haplotypes (haplogroup 3) were mainly found in these populations.

The pairwise differences in the interior populations (sites 18-23), in contrast, exhibited a bimodal distribution, although this result did not lead us to reject the sudden expansion model (Figure 4b). The main expansion event was estimated to have occurred at $\tau=13.2$ (95\% confidence interval, 6.3-23.7). The estimated expansion time in the interior region was thus 17 times that in the northeastern region. These estimates suggest that interior populations existed for a long period of time before they expanded towards the northeast.

\section{Discussion}

The interior as a refugium on the Qinghai-Tibetan Plateau Refugia, where species are able to survive for a long time, generally represent long-term reservoirs of the genetic variation of a species. In these locations, evolution often produces unique genotypes and high levels of diversity (Comes and Kadereit, 1998; Hewitt, 2000). We identified the interior as one such location on the Plateau for $P$. fruticosa. The following three pieces of evidence led to this conclusion: (1) the interior populations (sites 18-22) had widely divergent haplotypes (Figure 2); (2) these populations also exhibited high 
Table 2 Variable sites of the aligned sequences of the chloroplast DNA fragment matK region in the haplotypes of Potentilla fruticosa

Haplo- $16 \quad 2343 \quad 4998 \quad 110120149154160172216223233258317318 \quad 346 \quad 361 \quad 398 \quad 419446 \quad 478596 \quad 598 \quad 611 \quad 612643647674$ type

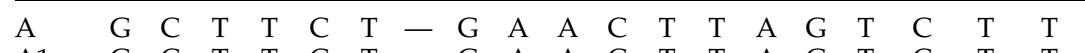

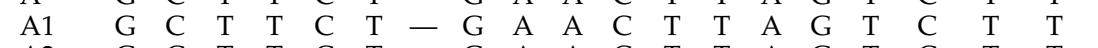

$\begin{array}{llllllllllllllllllll}\text { A2 } & \text { G } & \text { C } & \text { T } & \text { T } & \text { C } & \text { T } & - & \text { G } & \text { A } & \text { A } & \text { C } & \text { T } & \text { T } & \text { A } & \text { G } & \text { T } & \text { C } & \text { T } & \text { T } \\ \text { A3 } & \text { G } & \text { C } & \text { T } & \text { T } & \text { C } & \text { T } & - & \text { G } & \text { A } & \text { A } & \text { C } & \text { T } & \text { T } & \text { A } & \text { G } & \text { T } & \text { T } & \text { T } & \text { T }\end{array}$

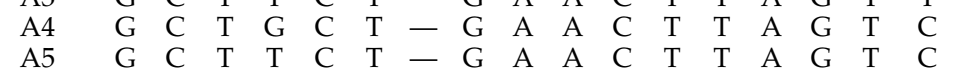

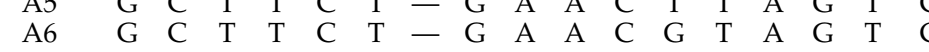

$\begin{array}{lllllllllllllllllll}\text { A7 } & \text { G } & C & \text { T } & \text { T } & C & \text { T } & - & \text { G } & \text { A } & \text { A } & C & \text { T } & \text { T } & \text { A } & G & \text { T } & C \\ \text { A8 } & \text { G } & \text { C } & \text { T } & \text { T } & \text { C } & \text { T } & - & \text { G } & \text { A } & \text { C } & \text { C } & \text { T } & \text { T } & \text { A } & \text { G } & \text { T } & \text { C }\end{array}$

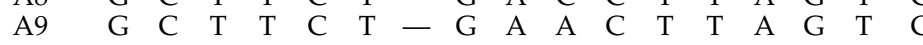

$\begin{array}{lllllllllllllllllllllllll}A 10 & G & C & T & T & C & T & - & G & C & A & C & T & T & A & G & T & C \\ B & G & C & T & T & C & T & - & G & A & A & C & T & T & A & G & T & C\end{array}$

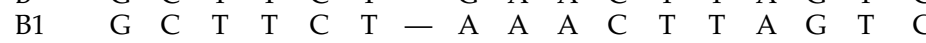

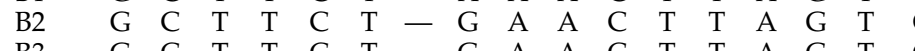

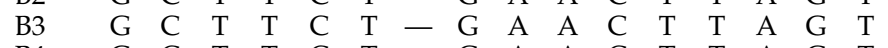

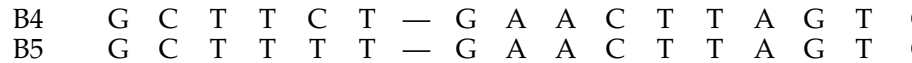

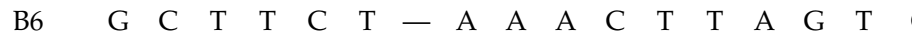

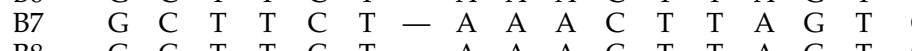

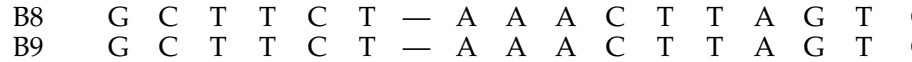

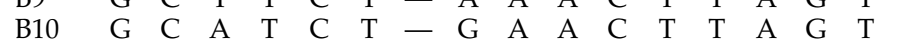

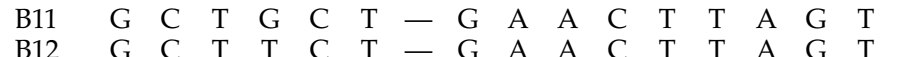

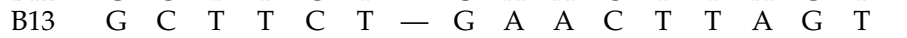

$\begin{array}{lllllllllllllllllllll}\mathrm{B} 14 & \mathrm{G} & \mathrm{C} & \mathrm{T} & \mathrm{T} & \mathrm{T} & \mathrm{T} & - & \mathrm{G} & \mathrm{A} & \mathrm{A} & \mathrm{C} & \mathrm{T} & \mathrm{T} & \mathrm{A} & \mathrm{G} & \mathrm{T} \\ \mathrm{C} & \mathrm{T} & \mathrm{T} & \mathrm{T} & \mathrm{T} & \mathrm{C} & \mathrm{T} & - & \mathrm{G} & \mathrm{A} & \mathrm{A} & \mathrm{C} & \mathrm{T} & \mathrm{C} & \mathrm{A} & \mathrm{G} & \mathrm{T}\end{array}$

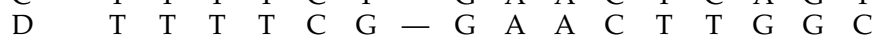

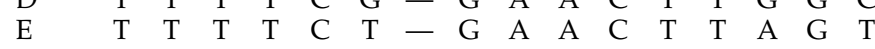

$\begin{array}{lllllllllllllllll}\mathrm{F} & \mathrm{T} & \mathrm{T} & \mathrm{T} & \mathrm{T} & \mathrm{C} & \mathrm{T} & - & \mathrm{G} & \mathrm{A} & \mathrm{A} & \mathrm{C} & \mathrm{T} & \mathrm{T} & \mathrm{A} & \mathrm{G} & \mathrm{T} \\ \mathrm{G} & \mathrm{T} & \mathrm{T} & \mathrm{T} & \mathrm{T} & \mathrm{C} & \mathrm{T} & - & \mathrm{G} & \mathrm{A} & \mathrm{A} & \mathrm{C} & \mathrm{T} & \mathrm{T} & \mathrm{A} & \mathrm{G} & \mathrm{T}\end{array}$

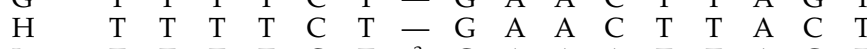

$\begin{array}{llllllllllllllllll}\mathrm{I} & \mathrm{T} & \mathrm{T} & \mathrm{T} & \mathrm{T} & \mathrm{C} & \mathrm{T} & \mathrm{a} & \mathrm{G} & \mathrm{A} & \mathrm{A} & \mathrm{A} & \mathrm{T} & \mathrm{T} & \mathrm{A} & \mathrm{G} & \mathrm{T}\end{array}$

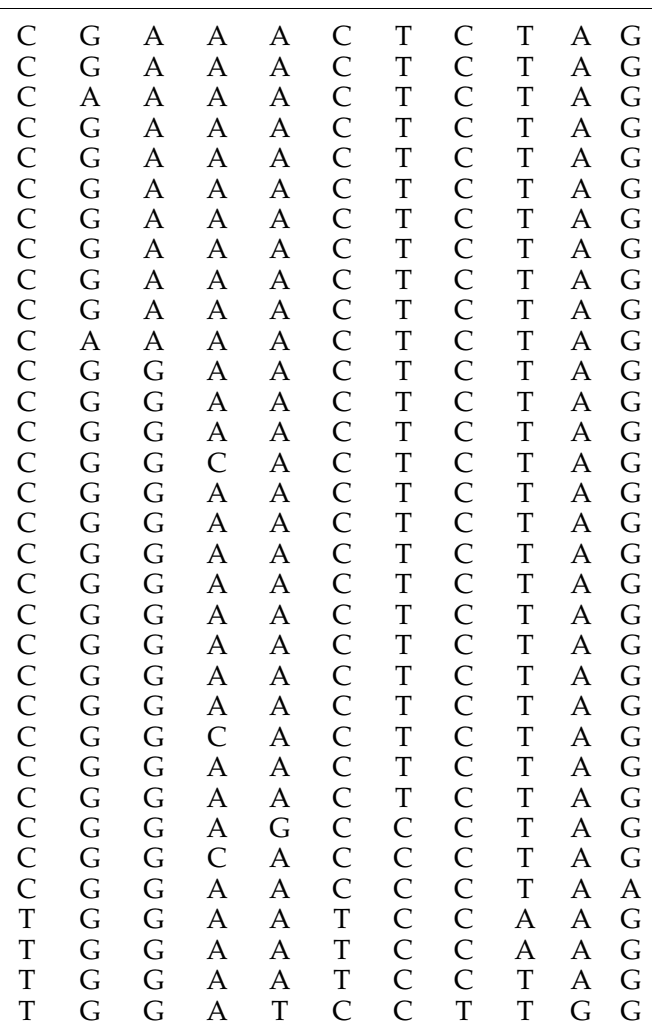

Haplo- 719732748750759760781805828835860885909912949960100410161019102810691085109011051106111211141121 type

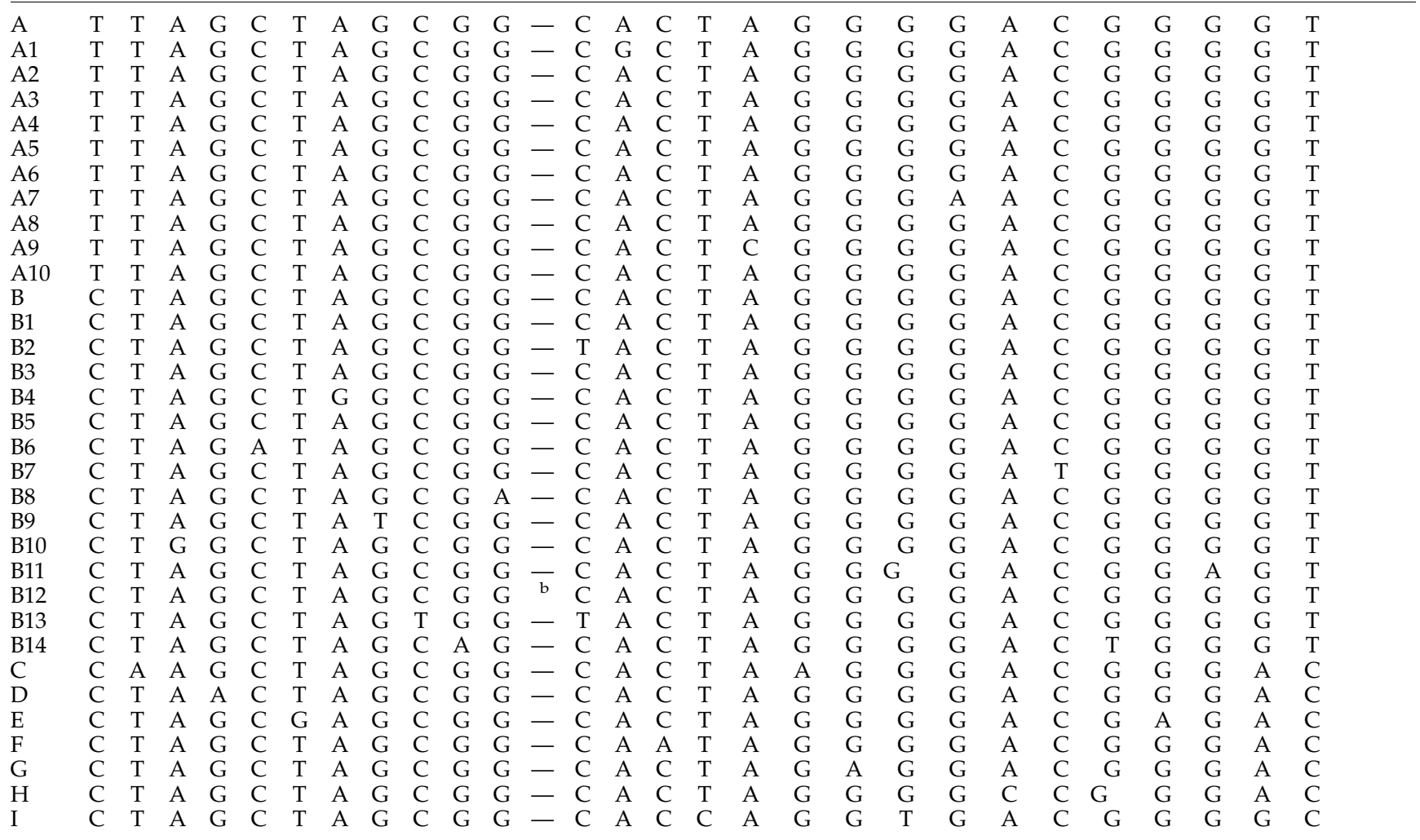




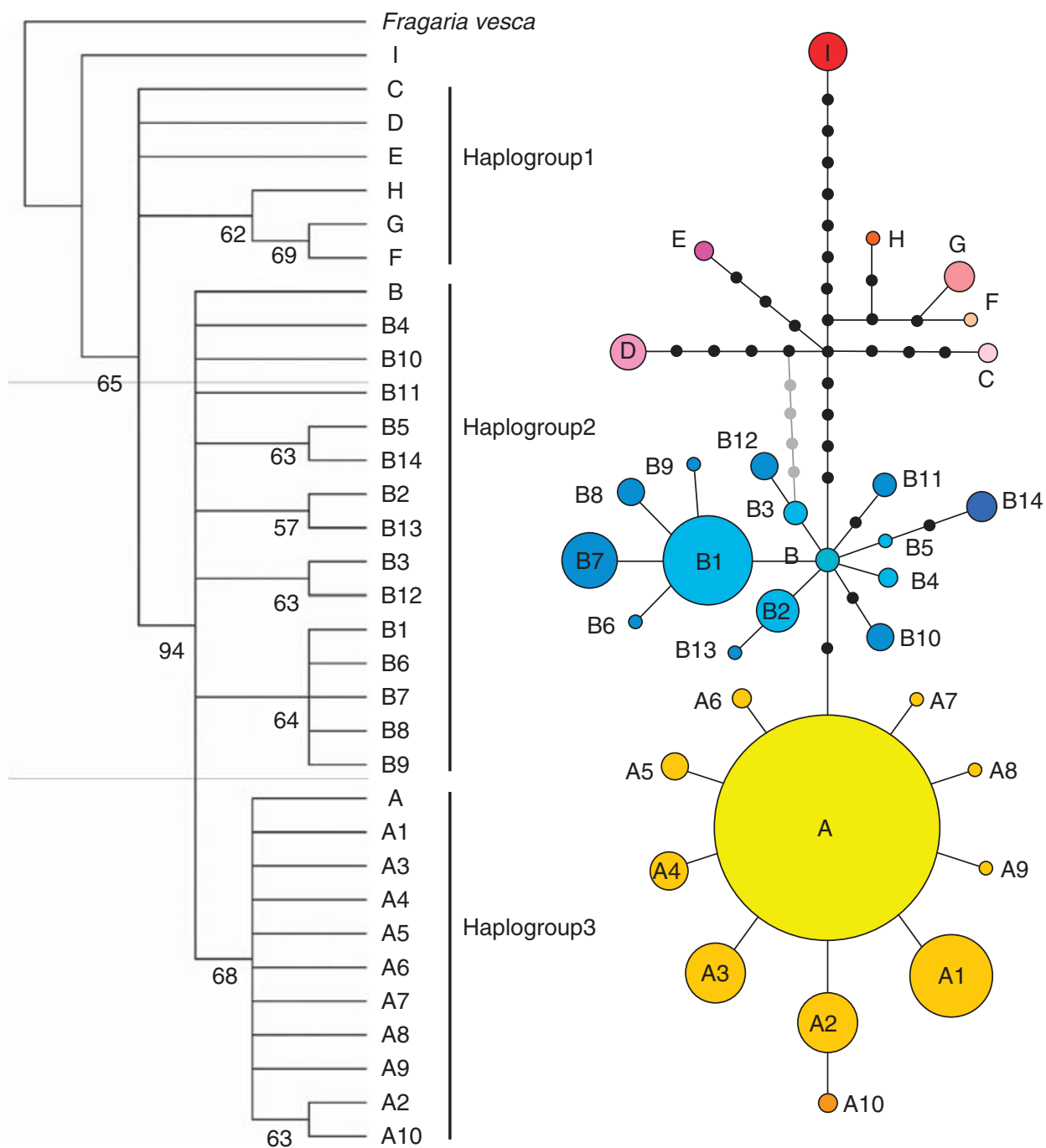

Figure 2 Phylogenetic relationships inferred among the cpDNA haplotypes of Potentilla fruticosa based on the sequences of the cpDNA matK region. Left: strict consensus tree of the 12 most-parsimonious trees. The numbers on the branches are bootstrap support values for 1000 replicates. Branches corresponding to partitions reproduced in $<50 \%$ of the bootstrap replicates are collapsed. Right: the haplotype networks. The sizes of circles correspond to the frequency of each haplotype. The small black circles on the branches represent the inferred intermediate haplotypes not observed in the samples. Grey line and dots indicate the network that was not supported by the phylogenetic tree. cpDNA, chloroplast DNA.

levels of genetic diversity (Table 1) and (3) within these populations, unique haplotypes were generally dominant and restricted to small areas (Figure 1). The high levels of diversity and unique genotypes in the interior region may also explain the clear tendency of genetic distances to increase towards the interior in the genetic landscape shape interpolation analysis (Figure 3). In particular, population 19 seems to be the longest surviving population in the sampling area of this study, because (1) it shows the highest genetic diversity among all populations (Table 1), (2) it harbours the ancestral haplotype I (Figures 1 and 2), and (3) clear genetic barriers exist between it and adjacent populations (Figure 3).

Palaeoenvironmental evidence also supports our view that the interior region may have served as a refugium for alpine species. The fossil pollen record shows that, during the mid-Holocene, when temperatures exceeded present-day temperatures by at least $1-2{ }^{\circ} \mathrm{C}$ (Yu et al.,
2000), forests were located at markedly higher elevations than they are today (Herzschuh et al., 2006; Ren, 2007). This phenomenon had probably occurred during each interglacial period. Therefore, at these times, alpine species in the eastern region must have withdrawn to unforested areas of relatively high altitude, such as in the interior region, where altitudes exceed $4500 \mathrm{~m}$.

The interior region probably provided a suitable habitat for P. fruticosa during glacial periods as well, because the Plateau was apparently not covered by massive ice sheets even during the last glacial maximum (Zheng et al., 2002). During the last glacial maximum, glaciers are estimated to have descended to $\sim 3500 \mathrm{~m}$ in the northeast and to $5000 \mathrm{~m}$ in the interior of the Plateau, reflecting the decreasing precipitation from east to west (Shi, 2002). These altitudes are more than $1000 \mathrm{~m}$ higher than those in the other regions at the same latitude (for example, Japan), partly as a result of the low precipitation in winter on the Plateau. 
540

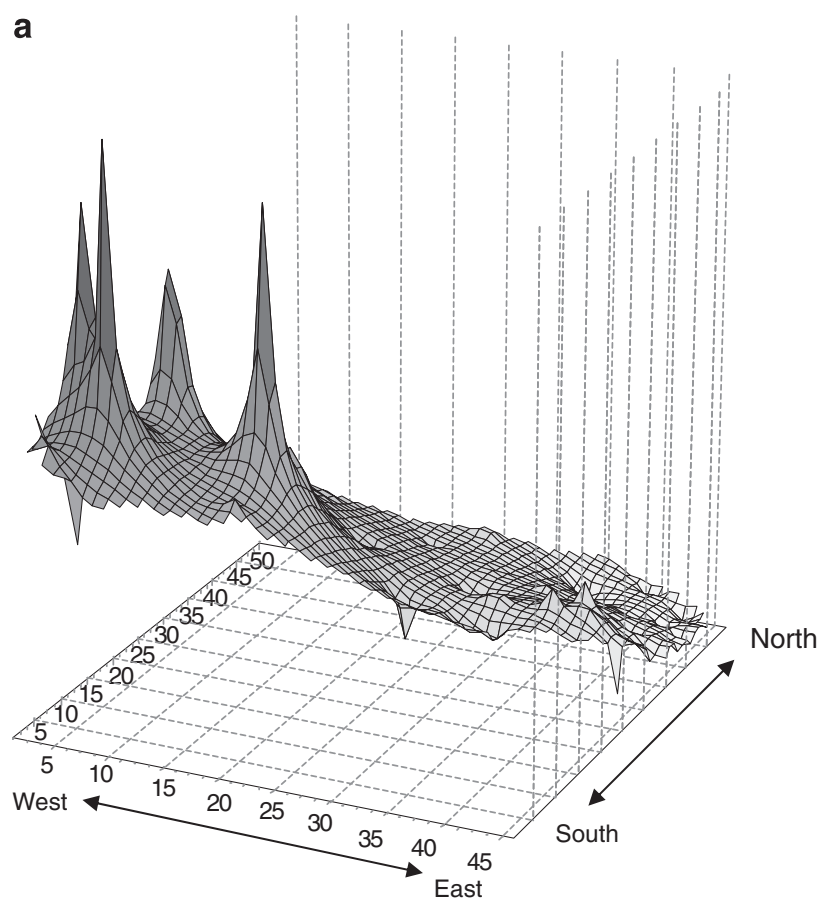

b

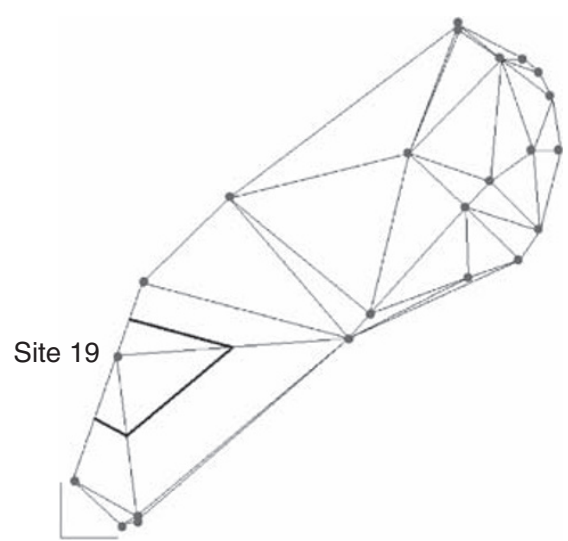

Figure 3 (a) Genetic landscape shape interpolation analysis using a $46 \times 50$ grid. $X$ and $Y$ axes correspond to geographical locations within the overall physical landscape examined in this study (Figure 1). Surface plot height ( $Z$ axis) reflects residual genetic distance. (b) Delaunay triangulation (fine lines) and the primary barriers (thick line). Dots indicate the sampling points. The greatest genetic barrier was detected between site 19 and its neighbours.

\section{Demographic history of $P$. fruticosa}

Past demographic and distributional changes of the alpine species are expected to be reflected in the genetic variations within and between populations. Our data strongly suggest that populations of $P$. fruticosa experienced drastic range expansions in response to past climatic fluctuations. The current northeastern populations apparently underwent a recent expansion from a restricted source area. This conclusion is supported by the unimodal mismatch distribution of the northeastern populations (Figure 4a), suggesting historical population expansion, and by the star-shaped phylogeny of haplotypes derived from haplotype A (Figure 2), the reduced levels of haplotypic and nucleotide diversity (Table 1), and the prevalence of haplotype $\mathrm{A}$ in the northeastern populations (Figure 1). The homogeneous genetic pattern a North-eastern region

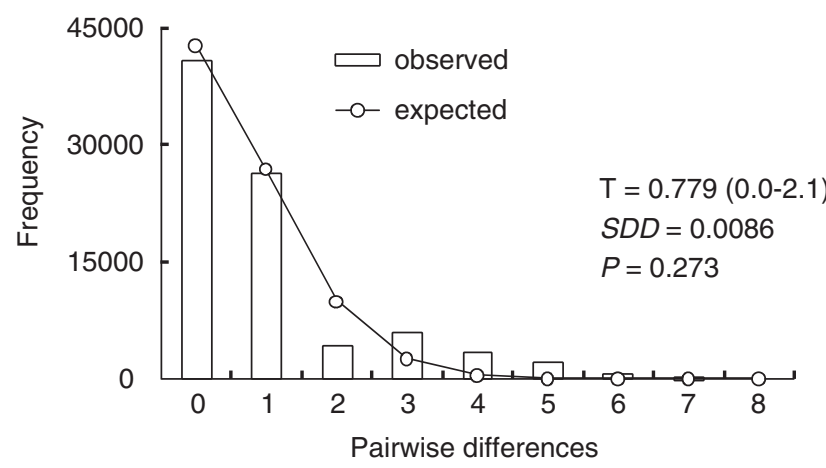

b Interior region

$\mathrm{T}=13.207$ (6.3-23.7)

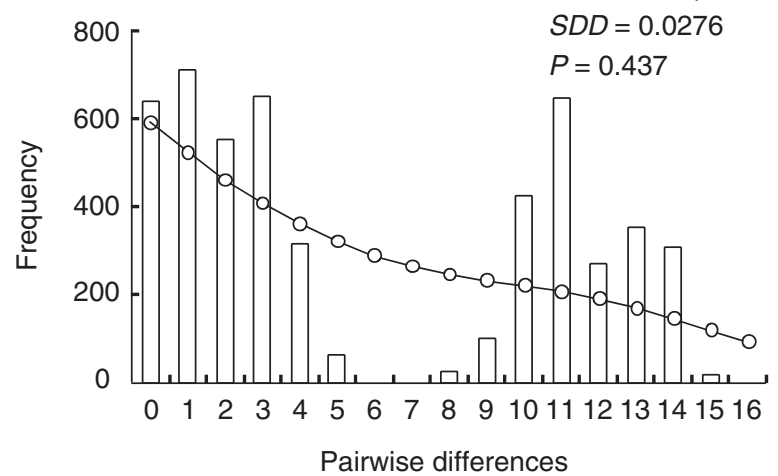

Figure 4 Mismatch distribution analysis for the (a) northeastern and (b) interior populations. Histograms correspond to observed frequencies of pairwise nucleotide differences, and lines represent the expected frequencies under the sudden expansion model. Goodness-of-fit of the observed versus the theoretical mismatch distributions under a sudden expansion model was tested using the sum of squared deviations (SDD). Upper and lower 95\% confidence limits around estimates of $\tau$ are given in parentheses.

in the northeastern populations is consistent with the AMOVA result, which showed relatively low genetic variation among populations $(48.7 \%)$ in comparison with other alpine plant species on the Plateau (Chen et al., 2008; Yang et al., 2008; Wang et al., 2009). These patterns are consistent with the results of a simulation study in which sudden expansion from a few populations produced reduced allele diversity and areas of genetic homogeneity (Avise, 2000).

This recent expansion most likely occurred after the beginning of the Holocene, as suggested by the fossil pollen record for the region. For example, a site at $3400 \mathrm{~m}$ on the eastern margin was covered by a cool mixed forest at $6 \mathrm{ka}$ B.P. (Yu et al., 2000). After 6 ka B.P., the forest cover decreased and alpine meadow became widely distributed in this region (Ren, 2007). At present, coniferous forest is located between 2000 and $2900 \mathrm{~m}$.

Phylogeographic studies suggest a similar history of coniferous trees (Zhang et al., 2005; Meng et al., 2007), the dominant species in the forested zone and which occasionally grow within the alpine zone on the northeastern Plateau. These scattered conifer populations probably reflect colonization from a refugial population that existed in the past along the Plateau's edge. In addition, results of a phylogeographic study of the alpine herb $A$. gymnandrum, which is widely 
distributed in alpine meadows across the Plateau, suggest the existence of refugia at high altitudes on the central Plateau (Wang et al., 2009). Conversely, refugia of another two alpine species were inferred to have been located at the Plateau's edge (Chen et al., 2008; Yang et al., 2008).

Further comparative studies with other regions and other species are required to confirm the history of alpine species on the Qinghai-Tibetan Plateau. Extensive studies conducted in high-latitude regions, especially in Europe, allow us to extract shared phenomena among species, although each species has its own unique history during glacial and interglacial periods (Schonswetter et al., 2005).

We also inferred that $P$. fruticosa populations probably experienced a demographic expansion before the recent expansion described above, and haplotype B prevailed across the Plateau. This scenario is supported by the star-shaped phylogeny exhibited by haplotypes derived from haplotype B (Figure 2) and by the occurrence of haplotype B in two disjunct areas, that is, in site 4 in the northeast and in sites 19 and 21 in the interior region (Figure 1). After the expansion, the P. fruticosa population would have contracted to the interior of the Plateau in response to climatic fluctuations, with the result that lineages derived from haplotype B would have been distributed mainly in interior regions, with only a few examples left in the northeast region (Figure 1). However, further studies are required to confirm this early range shift of the $P$. fruticosa population.

\section{Conclusions}

We reconstructed the demographic history of $P$. fruticosa on the Plateau by using genetic variation data obtained from spatially distributed populations. Our results suggest that periods of population expansion were associated with climatic cooling, and that during climatic warming, populations contracted to the interior of the Qinghai-Tibetan Plateau. Thus, the interior region acted as a refugium during interglacial periods, and greatly contributed to the diversification of $P$. fruticosa.

\section{Conflict of interest}

The authors declare no conflict of interest.

\section{Acknowledgements}

We thank Dr Shen Haihua, National Institute for Environmental Studies, who provided help with the sampling. We also thank Dr Takenaka, National Institute for Environmental Studies, for his helpful comments and encouragement. This study was funded in part by the Global Environment Research Coordination System, Ministry of the Environment, Government of Japan, for the project 'Early detection and prediction of climate warming based on long-term monitoring on the Tibetan Plateau', and by KAKENHI (Grant-in-Aid for Young Scientists (B) 19770020).

\section{References}

Abbott RJ, Brochmann C (2003). History and evolution of the arctic flora: in the footsteps of Eric Hulten. Mol Ecol 12: 299-313.
Assefa A, Ehrich D, Taberlet P, Nemomissa S, Brochmann C (2007). Pleistocene colonization of afro-alpine 'sky islands' by the arctic-alpine Arabis alpina. Heredity 99: 133-142.

Avise JC (2000). Phylogeography: The History and Formation of Species. Harvard University Press: Cambridge, MA.

Chen SY, Wu GL, Zhang DJ, Gao QB, Duan YZ, Zhang FQ et al. (2008). Potential refugium on the Qinghai-Tibet Plateau revealed by the chloroplast DNA phylogeography of the alpine species Metagentiana striata (Gentianaceae). Bot $J$ Linnean Soc 157: 125-140.

Clement M, Posada D, Crandall KA (2000). TCS: a computer program to estimate gene genealogies. Mol Ecol 9: 1657-1659.

Comes HP, Kadereit JW (1998). The effect of Quaternary climatic changes on plant distribution and evolution. Trends Plant Sci 3: 432-438.

DeChaine EG, Martin AP (2005). Marked genetic divergence among sky island populations of Sedum lanceolatum (Crassulaceae) in the Rocky Mountains. Am J Bot 92: 477-486.

Elkington TT, Woodell SRJ (1963). Potentilla fruticosa L. (Dasiphora fruticosa (L). RYDB). I Ecol 51: 769-781.

Eriksson T, Hibbs MS, Yoder AD, Delwiche CF, Donoghue M] (2003). The phylogeny of Rosoideae (Rosaceae) based on sequences of the internal transcribed spacers (ITS) of nuclear ribosomal DNA and the trnL/F region of chloroplast DNA. Int J Plant Sci 164: 197-211.

Excoffier L, Smouse PE, Quattro JM (1992). Analysis of molecular variance inferred from metric distances among DNA haplotypes-application to human mitochondrialDNA restriction data. Genetics 131: 479-491.

Guillen A, Rico E, Castroviejo S (1995). Reproductive biology of Iberian species of Potentilla L. (Rosaceae). Anales del Jardin Botanico de Madrid 62: 9-21.

Herzschuh U, Kurschner H, Mischke S (2006). Temperature variability and vertical vegetation belt shifts during the last similar to 50000 years in the Qilian Mountains (NE margin of the Tibetan Plateau, China). Quat Res 66: 133-146.

Hewitt GM (2000). The genetic legacy of the Quaternary ice ages. Nature 405: 907-913.

Hewitt GM (2004). Genetic consequences of climatic oscillations in the Quaternary. Philos Trans Roy Soc London B Biol Sci 359: 183-195.

Ikeda H, Senni K, Fujii N, Setoguchi H (2006). Refugia of Potentilla matsumurae (Rosaceae) located at high mountains in the Japanese archipelago. Mol Ecol 15: 3731-3740.

Koch MA, Kiefer C, Ehrich D, Vogel J, Brochmann C, Mummenhoff K (2006). Three times out of Asia Minor: the phylogeography of Arabis alpina L. (Brassicaceae). Mol Ecol 15: 825-839.

Lehmkuhl F, Owen LA (2005). Late Quaternary glaciation of Tibet and the bordering mountains: a review. Boreas 34: 87-100.

Li CL, Ikeda H, Ohba H (2003). Potentilla. In: Wu ZY, Raven, PH (eds). Flora of China, Vol. 9, Science Press: Beijing \& Missouri Botanical Garden Press: St Louis. pp 291-328.

Lopez-Pujol J, Zhang FM, Ge S (2006). Plant biodiversity in China: richly varied, endangered, and in need of conservation. Biodivers Conserv 15: 3983-4026.

Meng LH, Yang R, Abbott RJ, Miehe G, Hu TH, Liu JQ (2007). Mitochondrial and chloroplast phylogeography of Picea crassifolia Kom. (Pinaceae) in the Qinghai-Tibetan Plateau and adjacent highlands. Mol Ecol 16: 4128-4137.

Miller MP (2005). Alleles In Space (AIS): computer software for the joint analysis of interindividual spatial and genetic information. J Hered 96: 722-724.

Murray MG, Thompson WF (1980). Rapid isolation of high molecular weight plant DNA. Nucl Acid Res 8: 4321-4325.

Nei M (1987). Molecular Evolutionary Genetics. Columbia University Press: New York.

Ooi K, Endo Y, Yokoyama J, Murakami N (1995). Useful primer designs to amplify DNA fragments of the plastid gene matK from angiosperm plants. J Jpn Bot 70: 328-331. 
Petit RJ, Aguinagalde I, de Beaulieu JL, Bittkau C, Brewer S, Cheddadi $R$ et al. (2003). Glacial refugia: hotspots but not melting pots of genetic diversity. Science 300: 1563-1565.

Potter D, Gao F, Bortiri PE, Oh SH, Baggett S (2002). Phylogenetic relationships in Rosaceae inferred from chloroplast matK and trnL-trnF nucleotide sequence data. Plant Syst Evol 231: 77-89.

Ren GY (2007). Changes in forest cover in China during the Holocene. Veg Hist Archaeobot 16: 119-126.

Rogers AR, Harpending H (1992). Population growth makes waves in the distribution of pairwise genetic differences. Mol Biol Evol 9: 552-569.

Schneider S, Excoffier L (1999). Estimation of past demographic parameters from the distribution of pairwise differences when the mutation rates very among sites: application to human mitochondrial DNA. Genetics 152: 1079-1089.

Schneider S, Roessli D, Excoffier L (2000). Arlequin: A Software for Population Genetics Data Analysis. Ver 2.000. Genetics and Biometry Lab Department of Anthropology, University of Geneva.

Schonswetter P, Stehlik I, Holderegger R, Tribsch A (2005). Molecular evidence for glacial refugia of mountain plants in the European Alps. Mol Ecol 14: 3547-3555.

Shi Y (2002). Characteristics of late Quaternary monsoonal glaciation on the Tibetan Plateau and in East Asia. Quat Int 97-8: 79-91.

Soltis DE, Morris AB, McLachlan JS, Manos PS, Soltis PS (2006). Comparative phylogeography of unglaciated eastern North America. Mol Ecol 15: 4261-4293.
Swofford DL (2003). PAUP*: Phylogenetic Analysis Using Parsimony and Other Methods, version 4.0 beta version. Sinauer: Sunderland, Massachusetts.

Templeton AR, Crandall KA, Sing CF (1992). A cladistic analysis of phenotypic associations with haplotypes inferred from restriction endonuclease mapping and DNA sequence data. III. Cladogram estimation. Genetics 132: 619-633.

Thompson JD, Gibson TJ, Plewniak F, Jeanmougin F, Higgins DG (1997). The CLUSTAL_X windows interface: flexible strategies for multiple sequence alignment aided by quality analysis tools. Nucl Acid Res 25: 4876-4882.

Wang LY, Abbott RJ, Zheng W, Chen P, Wang YJ, Liu JQ (2009). History and evolution of alpine plants endemic to the Qinghai-Tibetan Plateau: Aconitum gymnandrum (Ranunculaceae). Mol Ecol 18: 709-721.

Yang FS, Li YF, Ding X, Wang XQ (2008). Extensive population expansion of Pedicularis longiflora (Orobanchaceae) on the Qinghai-Tibetan Plateau and its correlation with the Quaternary climate change. Mol Ecol 17: 5135-5145.

Yu G, Chen X, Ni J, Cheddadi R, Guiot J, Han H et al. (2000). Palaeovegetation of China: a pollen data-based synthesis for the mid-Holocene and last glacial maximum. J Biogeogr 27: 635-664.

Zhang Q, Chiang TY, George M, Liu JQ, Abbott RJ (2005). Phylogeography of the Qinghai-Tibetan Plateau endemic Juniperus przewalskii (Cupressaceae) inferred from chloroplast DNA sequence variation. Mol Ecol 14: 3513-3524.

Zheng BX, Xu QQ, Shen YP (2002). The relationship between climate change and Quaternary glacial cycles on the QinghaiTibetan Plateau: review and speculation. Quat Int 97-8: 93-101. 